\title{
Risk Perception of Septic Shock with Multiple Organ Failure Due to Acute Exacerbation of an Infectious Dental Disease
}

\author{
Hikaru Sato \\ Takashi Tamanoi \\ Takuya Suzuki \\ Hikaru Moriyama \\ Shota Abe \\ Kenji Yoshida \\ Hiroyoshi Kawaai \\ Shinya Yamazaki (D)
}

Department of Dental Anesthesiology, Ohu University, School of Dentistry, Koriyama City, Fukushima Prefecture, Japan
Correspondence: Shinya Yamazaki Department of Dental Anesthesiology, Ohu University, School of Dentistry, 3I-I Misumido, Tomita, Koriyama, Fukushima, 963-86II, Japan

Tel/Fax +81 249329337

Email zakiyama@ops.dti.ne.jp

\begin{abstract}
In general dental conditions such as dental caries and periodontal disease, a combination of adverse conditions can cause potentially life-threatening periodontal abscess. We treated a patient in whom an oral infection developed into septic shock, resulting in patient death. A 78-year-old woman experienced spontaneous pain around a moving tooth. Pus discharge was observed, the area was sterilized, and an analgesic was prescribed. A few days later, the swelling spread to the buccal region leading to difficulty while eating. Upon systemic status and blood examination at our dental hospital, depressed consciousness due to dehydration and septic shock were suspected. Oxygenation and infusion of acetate linger with antibiotics were immediately performed. Furthermore, a blood examination revealed malnutrition and a severe infection; therefore, the patient was transferred to a nearby general hospital. However, the patient died the next day because of advanced disseminated intravascular coagulation and multiple organ failure. When an oral infection is suspected in an elderly patient, antibiotics should be quickly administered, the patient's local and systemic state should be confirmed, and sterilization should be performed daily. If no improvement is observed, medical attention should be quickly sought.
\end{abstract}

Keywords: elderly malnutrition, immunological deterioration, infectious dental disease, multiple organ failure, sepsis-associated disseminated intravascular coagulation, risk management

\section{Introduction}

Dental conditions such as caries and periodontal disease are the most common diseases worldwide. ${ }^{1}$ However, combined adverse conditions can lead to lifethreatening periodontal abscess. ${ }^{2-10}$

As the population ages, the number of patients with systemic internal diseases also increases. Dental treatment and systemic perioperative management should be cautiously performed in elderly patients. Herein, we treated a patient who presented with septic shock symptoms caused by an infectious dental disease and who was transferred to a general hospital after undergoing emergency treatment but died the following day. In this report, it is necessary to inform the reader about the conditions and preventative measures against the aggravation of oral infection.

\section{Case Report}

A 78-year-old woman requested re-fabrication of the upper and lower partial dentures and underwent an initial examination at our general dental department 
on May 20. The patient had a medical history of hypertension, hyperlipidemia, and renal calculi and was taking trichlormethiazide, warfarin potassium, and fluvastatin sodium tablets; therefore, her blood pressure, lipid levels, and renal calculi were within normal ranges.

On July 16, the lower partial dentures were refabricated and re-fabrication of the upper partial dentures was planned once the adjustment of the lower partial dentures was complete.

On September 16, re-fabrication of the upper partial dentures was planned, but the patient was experiencing intense instability (tooth mobility level 3) in the upper left molar region, so the procedure was re-scheduled to take place after extraction of the tooth. At that point, no marked reddening or swelling of the upper left molar region was observed, and tooth extraction was scheduled to be performed at a later date. Dental X-rays (Figure 1) of the upper left molar region indicated marked alveolar bone resorption.

Subsequently, the patient experienced spontaneous pain and swelling in the upper left molar region and was examined at our general dental department on September 24. Pus discharge from the periodontal pocket was observed, and the area was cleaned and sterilized with normal saline solution and iodo-glycol paste. Loxoprofen sodium was prescribed as an analgesic.

A few days later, the swelling spread to the left buccal region and spontaneous pain became more intense, leading to more difficulty while eating for 2-3 days. On September 28, the primary care physician instructed the patient to visit our hospital. At 2:30 p.m. that day, upon examination at our general dental department, the Glasgow Coma Scale score was 11 . The patient was immediately referred to the dental anesthesiology department, and the physical findings included facial pallor, cold hands and fingers, and shivering. Palpation

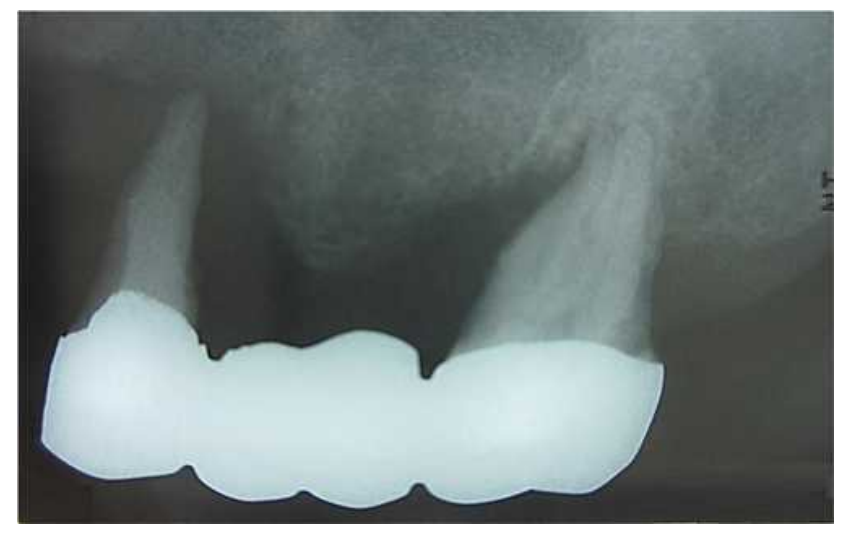

Figure I Dental X-ray of the patient's maxillary left region. indicated a weak radial artery pulse, and the vital signs were as follows: axillary temperature, $41^{\circ} \mathrm{C}$; systolic blood pressure, 80-90 mmHg; diastolic blood pressure, 40-50 $\mathrm{mmHg}$; pulse rate, $130-160 \mathrm{bpm}$; and $\mathrm{SpO}_{2}, 75 \%-85 \%$.

Based on the physical findings and vital signs, dehydration and septic shock were suspected. Therefore, oxygen administration at $10 \mathrm{~L} / \mathrm{min}$ was immediately initiated using a face mask. A venous line was secured to the cubital fossa after the blood was drawn for a rapid blood examination, and drip infusion of acetate linger solution $(500 \mathrm{~mL})$ and normal saline solution $(100 \mathrm{~mL})$ with ampicillin sodium (2 g) was initiated. Blood examination results are shown in Table 1. Malnutrition was suspected based on albumin (2.3 $\mathrm{g} / \mathrm{dL})$ and sodium $(127 \mathrm{mEq} / \mathrm{L})$ levels, and severe infection was suspected based on white blood cell count $(29,830 / \mu \mathrm{L})$ and C-reactive protein levels $(22.86 \mathrm{mg} / \mathrm{dL})$. After the venous infusion of antibacterial drugs, there were signs of improvement, and a consciousness level of 14 was observed on the Glasgow Coma Scale, with an axillary temperature of $38.5^{\circ} \mathrm{C}$, systolic blood pressure of $120-130 \mathrm{mmHg}$, diastolic blood pressure of $80-90 \mathrm{mmHg}$, pulse rate of $120-140$ bpm, and $\mathrm{SpO}_{2}$ of $100 \%$ when oxygen was administered at $10 \mathrm{~L} / \mathrm{min}$ using a face mask.

Subsequently, the patient was transferred to a nearby general hospital and blood examinations were performed; the results are shown in Table 2. High levels of D-dimer

Table I Results of Blood Examinations Taken at Our Hospital

\begin{tabular}{|c|c|}
\hline TP & $5.7 \mathrm{~g} / \mathrm{dL} \downarrow$ \\
\hline Alb & $2.3 \mathrm{~g} / \mathrm{dL} \downarrow$ \\
\hline BUN & $27.2 \mathrm{mg} / \mathrm{dL} \uparrow$ \\
\hline $\mathrm{Cr}$ & $0.63 \mathrm{mg} / \mathrm{dL}$ \\
\hline eGFR & $67.8 \mathrm{~mL} / \mathrm{min}$ \\
\hline AST & $39 \mathrm{IU} / \mathrm{L} \uparrow$ \\
\hline ALT & $28 \mathrm{IU} / \mathrm{L} \uparrow$ \\
\hline CPK & $20 \mathrm{I} I U / L \uparrow$ \\
\hline LDH & $310 \mathrm{IU} / \mathrm{L} \uparrow$ \\
\hline ALP & $420 \mathrm{IU} / \mathrm{L} \uparrow$ \\
\hline$\gamma$-GTP & $46 \mathrm{IU} / \mathrm{L}$ \\
\hline $\mathrm{Na}$ & $127 \mathrm{mEq} / \mathrm{L} \downarrow$ \\
\hline K & $4.4 \mathrm{mEq} / \mathrm{L}$ \\
\hline $\mathrm{Cl}$ & $90 \mathrm{mEq} / \mathrm{L} \downarrow$ \\
\hline Glu & $229 \mathrm{mg} / \mathrm{dL} \uparrow$ \\
\hline WBC & $29,830 \mu \mathrm{L} \uparrow$ \\
\hline RBC & $393 \times 10^{4} / \mu \mathrm{L}$ \\
\hline $\mathrm{Hb}$ & $11.8 \mathrm{~g} / \mathrm{dL}$ \\
\hline $\mathrm{Ht}$ & $34.4 \%$ \\
\hline PLT & $10.8 \times 10^{4} / \mu \mathrm{L} \downarrow$ \\
\hline CRP & $22.86 \mathrm{mg} / \mathrm{dL} \uparrow$ \\
\hline
\end{tabular}

Note: Each bold text indicates abnormal value. 
Table 2 Results of Blood Examinations Taken at the General Hospital

\begin{tabular}{|c|c|}
\hline TP & $4.6 \mathrm{~g} / \mathrm{dL} \downarrow$ \\
\hline Alb & $2.3 \mathrm{~g} / \mathrm{dL} \downarrow$ \\
\hline BUN & $27.2 \mathrm{mg} / \mathrm{dL} \uparrow$ \\
\hline $\mathrm{Cr}$ & $0.63 \mathrm{mg} / \mathrm{dL}$ \\
\hline eGFR & $76 \mathrm{~mL} / \mathrm{min}$ \\
\hline AST & $36 \mathrm{IU} / \mathrm{L} \uparrow$ \\
\hline ALT & $23 \mathrm{IU} / \mathrm{L}$ \\
\hline CPK & I 46 IU/L \\
\hline LDH & 254 IU/L $\uparrow$ \\
\hline ALP & $354 \mathrm{IU} / \mathrm{L} \uparrow$ \\
\hline$\gamma$-GTP & 37 IU/L $\uparrow$ \\
\hline $\mathrm{Na}$ & $128 \mathrm{mEq} / \mathrm{L} \downarrow$ \\
\hline K & $3.8 \mathrm{mEq} / \mathrm{L}$ \\
\hline $\mathrm{Cl}$ & $99 \mathrm{mEq} / \mathrm{L}$ \\
\hline Glu & $38.6 \mathrm{mg} / \mathrm{dL} \downarrow$ \\
\hline WBC & $19,740 / \mu \mathrm{L} \uparrow$ \\
\hline RBC & $334 \times 10^{4} / \mu L \downarrow$ \\
\hline $\mathrm{Hb}$ & $9.7 \mathrm{~g} / \mathrm{dL} \downarrow$ \\
\hline $\mathrm{Ht}$ & $29.2 \% \downarrow$ \\
\hline PLT & $9.1 \times 10^{4} / \mu \mathrm{L} \downarrow$ \\
\hline CRP & $17.96 \mathrm{mg} / \mathrm{dL} \uparrow$ \\
\hline FDP & $38.6 \mu \mathrm{g} / \mathrm{mL} \uparrow$ \\
\hline D-dimer & $23.98 \mu \mathrm{g} / \mathrm{mL} \uparrow$ \\
\hline
\end{tabular}

Note: Each bold text indicates abnormal value.

$(23.98 \mu \mathrm{g} / \mathrm{mL})$ and fibrin degradation products $(38.6 \mu \mathrm{g} /$ $\mathrm{mL}$ ) were found; thus, disseminated intravascular coagulation (DIC) was strongly suspected. Therefore, the patient underwent systemic management in intensive care unit. However, her condition worsened at around midday on the following day, and her death was confirmed at 9:22 p.m. on September 29.

On the following day, the patient's family requested an explanation regarding the treatment at our hospital. The general dentistry department manager, dental anesthesiologist, and relevant office staff explained the patient's course and state until the emergency transfer and the treatment that she was given, which her family understood. Furthermore, the family mentioned that the patient may have had lung cancer based on the findings of magnetic resonance imaging and computed tomography performed at the general hospital, which indicated pleural effusion, pulmonary infiltration, and pulmonary shadows. However, in accordance with the family's wish, histopathological testing and pathological autopsy were not performed. Then, written informed consent was obtained from the patient's family for the publication of the patient's case details. Then, this report was performed under the
Declaration of Helsinki and approved by Ohu university ethics committee.

\section{Discussion}

Routine dental maintenance at home or in a dental clinic is essential to prevent the exacerbation of periodontitis, because periodontal abscess is common in patients who neglect maintenance. ${ }^{11}$ The development of a periodontal abscess is a dental emergency, because it may cause gramnegative anaerobic bacteria to spread throughout the body. ${ }^{11}$ It is important to manage periodontitis appropriately so that it does not progress to an alveolar abscess requiring prompt medical intervention.

When the patient was examined at our hospital on September 24, spontaneous pain and swelling had occurred around a moving tooth and pus discharge was observed from the periodontal pocket. Although the area was cleaned and sterilized, no findings suggestive of worsening of the overall condition were noted. However, 4 days later, the patient was in a state of septic shock. Particularly, since 3 days prior to developing septic shock, the patient experienced difficult while eat and was unable to obtain adequate nutrition. Thus, the patient's rapid progression from dental infection to dehydration and septicemia may have been related to the difficulty while eating for 3 days.

After developing septic shock, the patient was taken to the hospital and it was determined that she was in a serious state based on the physical findings and vital signs. After our intervention, there was improvement and the patient was transferred to the general hospital. However, there are several other points that need to be reviewed regarding our treatment.

There are many issues related to infections in elderly patients; however, Martín et $\mathrm{al}^{2}$ cited the following three characteristics to be particularly important: 1) decreased immune function related to age, 2) accompanying malnutrition, and 3 ) high mortality rate associated with infection. Our patient was old (78 years), and the above mentioned points might be applicable to her. There are some reports wherein oral infections have developed to septicemia or DIC. ${ }^{3-10}$ The common points in such reports are as follows: 1) elderly patient, 2) oral cavity as the source of infection, 3) associated malnutrition, and 4) complications of diabetes or malignant neoplasms. One of these reports described an elderly patient in whom an alveolar abscess was suddenly complicated by septicemia resulting in DIC 
and subsequent death. ${ }^{3}$ Therefore, even in a patient with a simple alveolar abscess, the fact that various complicating factors might be involved if the patient is elderly needs to be considered and careful treatment needs to be implemented. Another report described an elderly patient in whom root canal treatment was performed to treat tooth pain, which resulted in inflammation that rapidly spread to the cheek and neck regions; thereafter, septic shock resulted in death. ${ }^{4}$ Therefore, during routine endodontic treatment and in the case of alveolar abscess, if the patient is elderly, the general condition must be considered and careful treatment should be implemented.

Carter and Lowis ${ }^{5}$ suggested that a patient's death after rapid development of septicemia by dental infection is caused by decreased immune function due to chronic lymphocytic leukemia. Accordingly, in elderly individuals who generally have low immune function and are in a suboptimal nutritional state, healthcare providers need to keep in mind that infection exhibits dramatic progression if a patient has a malignant neoplasm. A definitive diagnosis could not be made because our patient's family did not allow an autopsy to be performed; however, diagnostic imaging of the chest showed pleural effusion, pulmonary infiltration, and pulmonary shadow. Thus, there is a possibility of a malignant neoplasm that might have been the reason for the dramatic progression of septicemia.

In one report on post-extraction infection related to diabetes, the patient's life was saved because of early intensive treatment despite complications of septicemia and DIC. ${ }^{6}$ Generally, the likelihood of saving a patient's life markedly drops once septicemia is complicated by DIC. However, the aforementioned report indicates that doctors and dentists should co-operate with each other to accurately understand a patient's general state; if there is no improvement of symptoms, a diagnosis should be made without delay and intensive treatment should be initiated.

Our findings indicate that in actual clinical practice, antibacterial drugs should be immediately administered to elderly patients who exhibit signs of oral infection such as abscess or pus discharge. Sterilization should be continuously and daily performed while carefully monitoring the patient's progress. In addition, it should be checked if the patient is receiving adequate nutrition and is well hydrated. If the oral infection does not improve despite treatment or the patient is not receiving adequate nutrition, it is important for healthcare providers to be aware that the condition can easily progress to septicemia and thus should co-operate with a general hospital that can offer intensive care to manage such patients.

Moreover, these findings suggested that asymmetric dimethylarginine (ADMA), soluble urokinase-type plasminogen activator receptor (suPAR), and Aggregatibacter actinomycetemcomitans (AA) have significantly strong associations with systemic diseases such as periodontal disease and cardiovascular disease. ${ }^{12-14}$ High-risk patients should be assessed carefully with the appropriate tests to detect ADMA, suPAR, and AA, in addition to the WBC and CRP tests, which are conventionally used as indicators of infection.

Furthermore, several studies have reported that infection significantly worsens the prognosis in HIV-positive patients. ${ }^{15-17}$ Follow-up of patients with oral implants should be conducted, because oral infection is likely to worsen in this patient group. It has been reported that it is useful to completely cover the surface of the wound with a biomaterial during invasive procedures in patients who are at high risks of aggravation of oral infection ${ }^{18}$ and it has been suggested that implant placement techniques may also prevent infection. ${ }^{19-21}$

\section{Conclusion}

Even in cases of general dental diseases such as caries and periodontal disease, the combination of adverse conditions may cause a life-threatening periodontal abscess. To prevent such diseases, it is important to use various tests and technologies to prevent the aggravation of infection from caries and periodontal disease and their progress to the stage of periodontal abscess.

In elderly patients who often have decreased immune function, suboptimal nutritional state, and various systemic complications, oral infections are prone to develop into septicemia or DIC. Accordingly, when an oral infection is suspected in an elderly patient, antibacterial drugs should be immediately administered, the patient's local and systemic states should be confirmed, sterilization should be daily performed, and if no improvement is observed, the cooperation of a medical department should be quickly sought.

\section{Disclosure}

The authors report no conflicts of interest in this work. 


\section{References}

1. Peres MA, Macpherson LMD, Weyant RJ, et al. Oral diseases: a global public health challenge. Lancet. 2019;394:249-260. doi:10.1016/S0140-6736(19)31146-8

2. Martín S, Pérez A, Aldecoa C. Sepsis and immunosenescence in the elderly patient: a review. Front Med. 2017;4:20. doi:10.3389/ fmed.2017.00020

3. Shimizu G, Chisoku H, Fujita Y, Ota Y, Kato I, Yura Y. A case of septic pulmonary embolism with disseminated intravascular coagulation due to severe odontogenic infection. Jpn J Oral Maxillofac Surg. 2014;60(6):359-364. doi:10.5794/jjoms.60.359

4. Fujii K, Imai K, Tomaru Y, et al. A case of septic shock following root canal procedure performed during house call treatment. $J$ Jpn Soc Dent Med Compromise Patient. 2005;14(2):81-86.

5. Carter L, Lowis E. Death from overwhelming odontogenic sepsis: a case report. Br Dent J. 2007;203(5):241-242. doi:10.1038/bdj.2007.784

6. Yoshida R, Nakayama H, Nagata M, Yoshitake Y, Teshima K, Shinohara M. A case of septic pulmonary embolism caused by odontogenic infection. Jpn J Oral Maxillofac Surg. 2010;56 (1):49-53. doi:10.5794/jjoms.56.49

7. Tsuji K, Shima M, Gamoh S, et al. A deceased case associated with sepsis arised from streptococcus milleri group according to bisphsophonate related osteonecrosis of the maxilla. Taisei Gakuin Univ Bulle. 2015;17(34):197-201.

8. Ocampo FP, Limon MAL, Bustillos LJ, Silva SV. Death from generalized sepsis of dental origin. Contribution to clinical casuistry. $\mathrm{Br}$ J Oral Maxillofac Surg. 1991;48(1):45-51

9. Currie WJ, Ho V. An unexpected death associated with an acute dentoalveolar abscess - report of a case. Br J Oral Maxillofac Surg. 1993;31(5):296-298. doi:10.1016/0266-4356(93)90063-3

10. Juncar M, Popa AR, Lung T, Onişor F. Septic metastases of suppuration of odontogenic origin. Chirurgia. 2011;106(3):359-364.

11. Herrera D, Roldán S, Sanz M. The periodontal abscess: a review. $J$ Clin Periodontol. 2000;27(6):377-386. doi:10.1034/j.1600051x.2000.027006377.x

12. Isola G, Alibrandi A, Currò $M$, et al. Evaluation of salivary and serum ADMA levels in patients with periodontal and cardiovascular disease as subclinical marker of cardiovascular risk. $J$ Periodontol. 2020;91(8):1076-1084. doi:10.1002/JPER.19-0446
13. Isola G, Polizzi A, Alibrandi A, Williams RC, Leonardi R. Independent impact of periodontitis and cardiovascular disease on elevated soluble urokinase-type plasminogen activator receptor (suPAR) levels. J Periodontol. 2020. doi:10.1002/JPER.20-0242

14. Isola G, Polizzi A, Patini R, Ferlito S, Alibrandi A, Palazzo G. Association among serum and salivary A. actinomycetemcomitans specific immunoglobulin antibodies and periodontitis. BMC Oral Health. 2020;20(1):283. doi:10.1186/s12903-020-01258-5

15. Gherlone EF, Capparé P, Tecco S, et al. A prospective longitudinal study on implant prosthetic rehabilitation in controlled HIV-positive patients with 1-year follow-up: the role of CD4+ level, smoking habits, and oral hygiene. Clin Implant Dent Relat Res. 2016;18 (5):955-964. doi:10.1111/cid.12370

16. Gherlone EF, Capparé $\mathrm{P}$, Tecco $\mathrm{S}$, et al. Implant prosthetic rehabilitation in controlled HIV-positive patients: a prospective longitudinal study with 1-year follow-up. Clin Implant Dent Relat Res. 2016;18 (4):725-734. doi:10.1111/cid.12353

17. Capparé P, Teté G, Romanos GE, Nagni M, Sannino G, Gherlone EF. The 'All-on-four' protocol in HIV-positive patients: a prospective, longitudinal 7-year clinical study. Int J Oral Implantol. 2019;12 (4):501-510.

18. Crespi R, Capparé P, Romanos GE, Mariani E, Benasciutti E, Gherlone E. Corticocancellous porcine bone in the healing of human extraction sockets: combining histomorphometry with osteoblast gene expression profiles in vivo. Int J Oral Maxillofac Implants. 2011;26(4):866-872.

19. Bruschi GB, Crespi R, Capparè P, Bravi F, Bruschi E, Gherlone E. Localized management of sinus floor technique for implant placement in fresh molar sockets. Clin Implant Dent Relat Res. 2013;15 (2):243-250. doi:10.1111/j.1708-8208.2011.00348.x

20. Bruschi GB, Crespi R, Capparè P, Gherlone E. Transcrestal sinus floor elevation: a retrospective study of 46 patients up to 16 years. Clin Implant Dent Relat Res. 2012;14(5):759-767. doi:10.1111/ j.1708-8208.2010.00313.x

21. Crespi R, Capparè P, Gherlone E. Sinus floor elevation by osteotome: hand mallet versus electric mallet. A prospective clinical study. Int J Oral Maxillofac Implants. 2012;27(5):1144-1150.
Therapeutics and Clinical Risk Management

\section{Publish your work in this journal}

Therapeutics and Clinical Risk Management is an international, peerreviewed journal of clinical therapeutics and risk management, focusing on concise rapid reporting of clinical studies in all therapeutic areas, outcomes, safety, and programs for the effective, safe, and sustained use of medicines. This journal is indexed on PubMed Central, CAS,

\section{Dovepress}

EMBase, Scopus and the Elsevier Bibliographic databases. The manuscript management system is completely online and includes a very quick and fair peer-review system, which is all easy to use. Visit http://www.dovepress.com/testimonials.php to read real quotes from published authors. 